\section{El empleo de las personas con diversidad funcional en la prensa: ABC y El País $(1978-2012)^{1}$}

\section{Coverage of the employment of people with functional diversity in the press: $\mathrm{ABC}$ and $\mathrm{El}$ País newspapers (1978-2012)}

\begin{abstract}
Resumen
Este artículo presenta los resultados de los análisis realizados en relación con el conjunto de noticias relacionadas con el empleo ordinario y protegido de las personas con diversidad funcional, correspondientes a una muestra seleccionada en los periódicos ABC y El PAÍS entre I978 y 20I 2. El empleo es un tema muy presente en la prensa a través de noticias que ofrecen porcentajes de personas con diversidad funcional desempleadas, historias personales de éxito laboral, la opinión del empresariado, el incumplimiento de la legislación, las reivindicaciones del movimiento asociativo, los centros especiales de empleo, etc. Un argumento comúnmente repetido es la valoración del empleo como medio de integración social y normalización. En una sociedad capitalista esa "normalidad" pasa por producir un valor económico para conseguir un beneficio con el que poder consumir bienes y servicios. Los discursos hallados en las noticias han sido complementados con la legislación más relevante y han sido contrastados con los datos secundarios disponibles en materia de empleo.
\end{abstract}

\section{Palabras clave}

Diversidad funcional, discapacidad, empleo, legislación, medios de comunicación.

\begin{abstract}
This paper presents the results of analyses performed on news articles related to ordinary and protected employment for people with functional diversity in a sample taken from $\mathrm{ABC}$ and El País newspapers between I978 and 20I2. Employment is a common topic covered in the press and present in news that reports on percentages of unemployed people with functional diversity, personal stories of job success, opinions on the business sector, the failure of legislation, demands of associations, and special employment centers. A common theme is employment as a measure of social integration and normalization, which is understood in a capitalist society to mean the ability to produce an economic value to make earnings for acquiring goods and services. The speeches obtained have been supplemented with relevant legislation and have been contrasted with available secondary data on employment.
\end{abstract}

\section{Keywords}

Functional diversity, disability, employment, legislation, media.
I. Este artículo se basa en la comunicación presentada en el Congreso de la Red Española de Política Social, celebrado en Barcelona 5-6 de Febrero de 2015, en el panel "Políticas Sociales y Discapacidad", cuya coordinación estuvo a cargo de Eduardo Díaz y Ángel Belzunegui.

\section{Borja González Luna \\ <bgonlun@gmail.com>}

Universidad Complutense de Madrid

\section{Antonio láñez Domínguez <aiadom@upo.es>}

Universidad Pablo de Olavide, Sevilla
Para citar:

González, B. y Iáñez, A. (20I 5): “El empleo de las personas con diversidad funcional en la prensa: ABC y El País (I978-20I2)", Revista Española de Discapacidad, 3 (I): 57-76.

Doi: <http://dx.doi.org/IO.5569/23405 IO4.03.0I.03>

Fecha de recepción: I2-02-20I5 Fecha de aceptación: OI-O6-20I 5 


\section{Introducción}

La imagen de la diversidad funcional ha sido construida social y culturalmente a lo largo de los años desde diversos espacios (político, legislativo, asociativo, educativo, laboral, académico). En esa construcción, los medios de comunicación -como productores y generadores de estados de opinión- han jugado y juegan un papel importante. Los/as periodistas son conscientes de cómo influyen sus mensajes en la conformación de la idea que tienen las personas sobre un determinado fenómeno. Analizando e interpretando el tratamiento otorgado a la diversidad funcional en ese espacio comunicacional, se puede llegar a conocer cómo ha sido la representación de la misma y su evolución a lo largo del periodo analizado.

La importancia del papel de los medios de comunicación en la construcción de la realidad fue lo que nos llevó a realizar la investigación financiada por la Asociación Roosevelt con motivo de la XII Beca de investigación, que tuvo por objetivo analizar la imagen y el tratamiento dado a la diversidad funcional física en la prensa española, en concreto, a través del análisis de las noticias publicadas en dos periódicos nacionales: ABC y El País, en el periodo comprendido entre I 978 y 2012.

Del conjunto de noticias analizadas (un total de 435), para este artículo se han seleccionado las noticias concernidas con el empleo, relacionándolas con la legislación más relevante en la materia, y contrastándolas con datos secundarios obtenidos de diferentes fuentes documentales y estadísticas. Se quiere, por tanto, mostrar cuál ha sido la presencia de las políticas públicas sobre empleo y diversidad funcional en la prensa en las últimas décadas, a través de los dos periódicos seleccionados. Y cómo se han construido los discursos en torno a su integración laboral, en sentido general. Aunque el objeto y el diseño de la investigación partieron del grupo específico de personas con diversidad física, los resultados se pueden hacer extensibles, en la mayoría de los hechos al resto de diversidades funcionales.
Antes de pasar a exponer la metodología y los resultados, sirva esta introducción para aclarar el uso que hacemos -y que da título al artículodel término diversidad funcional. Tiene su origen en los debates generados entre los/as miembros del Foro de Vida Independiente y Divertad $^{2}$, y surge con la intención de crear un término que evite las connotaciones negativas y peyorativas que contemplan los utilizados hasta ese momento para denominar a este grupo (inválido, inútil, minusválido, discapacitado, etc.). "El término persona con diversidad funcional es definido desde dentro, siendo la primera denominación de la historia en la que no se da un carácter negativo ni médico a la visión de una realidad humana" (Iáñez, 20I0: 62). Según Romañach y Lobato (2005: 4) "el término diversidad funcional se ajusta a una realidad en la que una persona funciona de manera diferente o diversa de la mayoría de la sociedad". Es por todo ello que optamos por este término, aunque mantendremos todos aquellos otros tal cual aparecen en las noticias, las bases de datos, los discursos, etc., con objeto de ser fieles a las referencias que utilizamos y al contexto histórico en el que fueron empleados.

\section{Metodología}

Para realizar el análisis de la "representación de la diversidad funcional física en la prensa” se optó por elaborar una muestra de noticias ${ }^{3}$ de los periódicos nacionales ABC y El País, por considerarse que ambos periódicos representan los diarios de mayor tirada para el periodo analizado que comprende el intervalo de I978 a 2012.

2. Este Foro se crea en el año 200I, como una comunidad virtual que sirve para la reflexión, la ayuda mutua y la construcción de conocimientos acerca de todo lo relacionado con la diversidad funcional.

3. Las unidades de análisis no solo se correspondieron con noticias, en un sentido estricto, también han sido analizados editoriales, artículos de opinión, reportajes, y cartas al director. 
Para la búsqueda y selección de las unidades de análisis hemos utilizado los buscadores con los que cuenta cada periódico en su página web Para usar correctamente dichos buscadores y acercarnos al objeto de estudio de nuestra investigación definimos cuáles podrían ser, según un criterio que tuviera en cuenta la evolución terminológica, los «términos clave» para diversificar la forma de búsqueda a través de dichos buscadores. La idea era que diferentes términos nos remitirían a diferentes momentos históricos que se tenían que ver reflejados en la prensa analizada; los términos utilizados fueron: "disminuidos físicos", "minusválidos físicos", "discapacidad física" y "diversidad funcional". A continuación creamos una tabla con todas las unidades de análisis aparecidas en cada periódico por cada término clave y año, que nos sirvió para establecer la proporción de unidades de análisis que íbamos a seleccionar.

El criterio de selección de dichas unidades consistió en atender a un orden de jerarquía de los diferentes estilos periodísticos: editorial, artículo de opinión, reportaje, crónica y noticia, es decir, cada estilo periodístico, en el orden de jerarquía establecido, funcionaba de filtro para la selección de la cuota correspondiente a cada año. El principio de selección de las unidades de análisis fue optar, en primer lugar, por aquellas unidades de análisis que contienen un mayor contenido discursivo, frente a las noticias, en sentido estricto, que muestran un contenido más descriptivo y objetivista -aunque fueron estas últimas las unidades de análisis que obtuvieron mayor representación-. En el transcurso de la selección, decidimos incorporar también las cartas al director y las entrevistas a personas con diversidad funcional como unidades de análisis "extras", es decir, que no contabilizaron dentro de las cuotas establecidas de forma proporcional. La muestra quedó constituida por un total de 435 noticias: 202 en ABC y 233 en El País.

4. Para ABC: http://www.abc.es/ Para El País: http://elpais. com/
Tabla 1. Unidades de análisis seleccionadas por periódico (cada cuatro años)

\begin{tabular}{|l|c|c|c|}
\hline AÑo & ABC & EL PAís & Total \\
\hline $1978-1981$ & 18 & 13 & 31 \\
\hline $1982-1985$ & 11 & 15 & 26 \\
\hline $1986-1989$ & 28 & 11 & 39 \\
\hline $1990-1993$ & 32 & 11 & 43 \\
\hline $1994-1997$ & 25 & 31 & 56 \\
\hline $1998-2001$ & 23 & 44 & 67 \\
\hline $2002-2005$ & 20 & 38 & 58 \\
\hline $2006-2009$ & 25 & 36 & 61 \\
\hline $2010-2012$ & 20 & 34 & 54 \\
\hline Total & 202 & 233 & 435 \\
\hline
\end{tabular}

Fuente: elaboración propia.

Las noticias fueron analizadas desde dos perspectivas: (I) análisis del contenido y (2) análisis del discurso. Se definieron una serie de categorías específicas para ser identificadas en cada noticia y poder con ello obtener resultados representativos. Las principales categorías fueron: terminología, titular, sección, género periodístico, temática y modelos. El análisis de contenido ha permitido información más cuantitativa, registrándose la información en una base de datos Excel; y el análisis del discurso, utilizando el programa informático Atlas.ti, ha facilitado un análisis cualitativo de las disertaciones realizadas por representantes de entidades del sector, representantes políticos, de sindicatos, de periodistas, etc.

Para este artículo se han seleccionado concretamente todas las unidades de análisis que trataban sobre empleo ordinario y protegido: un total de 52 unidades de análisis. Si bien nuestra investigación ha estado centrada en la diversidad funcional física, un volumen importante de noticias trataba la diversidad funcional de forma genérica, esto es, no se hacía la distinción si era física, intelectual, sensorial y/o mental, sobre todo, cuando las noticias referían a cuestiones legislativas, estadísticas, etc. Es el caso del 
empleo, en el que el contenido de las noticias ha girado en torno a la presentación de las tasas de desempleo en la que se hallaba este grupo, casos particulares de personas que, por el contrario, tienen "éxito" laboral, sobre el incumplimiento de la LISMI, los debates sobre la reserva de cupo, sobre el empresariado, sobre los centros especiales de empleo, etc.

Para ofrecer una mayor consistencia a la información y los discursos hallados en las noticias, hemos recurrido a la legislación más relevante y a fuentes documentales y estadísticas en materia de empleo. En este sentido, queremos señalar que las reflexiones que exponemos a continuación tratan de hacer balance del tratamiento que ha tenido el empleo de las personas con diversidad funcional en la prensa durante las últimas décadas.

\section{Empleo ordinario en empresas privadas y públicas}

Para concretar mejor el análisis de las noticias seleccionadas en relación con el empleo ordinario hemos organizado la información en tres subapartados que comprenden la década de los 80 y 90 del siglo XX y primera década del siglo XXI.

\subsection{Década de los 80}

La década de los 80 se abre, en España, con una tasa de paro del I I, I \% de la población activa total, alcanza su máximo en 1985 con una tasa del 2 I \%, y dicha década se cierra con un I $7 \%$. En esta década, en algunas ofertas de trabajo se puede leer: "se excluirá todo aquel que reúna impedimento físico o psíquico"s.

5. "Los minusválidos y su conflictiva integración en las ciudades" (ABC 25/07/1982).
La primera noticia, en relación con el empleo, aparece el 22 de Febrero de $1979^{6}$. Este es un momento en el que sucede la reestructuración de organismos, instituciones y ministerios del Estado como consecuencia de las transformaciones democráticas que acontecen en España. Se disuelve la Asociación Nacional de Inválidos Civiles (ANIC) y sus trabajadores pasan a formar parte del Servicio de Recuperación y Rehabilitación de Minusválidos (SEREM) de la Seguridad Social. En dicho contexto de reestructuración del Estado español se aprobará la Ley de Integración Social de los Minusválidos, conocida con las siglas LISMI, el 7 de Abril de 1982, que será el texto de referencia en materia laboral durante las décadas de los 80 y 90 .

Durante la década de los 80 aparece reflejado en la prensa un conflicto en relación con la aparición de nuevas entidades que quieren gestionar cupones de lotería como forma de integración laboral. La ONCE se opone a que existan nuevas entidades que gestionen un nuevo cupón de loterías:

"El Consejo General de la Organización Nacional de Ciegos y la Coordinadora Estatal de Minusválidos Físicos han denunciado al Gobierno el desarrollo de formas fraudulentas del juego, así como la explotación de minusválidos y la insuficiencia del marco jurídico para paliar estos problemas” ${ }^{7}$.

En I986 acontece la desmantelación de la Red de Loterías de PRODIECU (Promoción y Difusión de Entidades Culturales) y APEM (Asociación para Promoción del Empleo al Minusválido). Según Pedro Fuentes, Jefe de prensa de PRODIECU y APEM:

"Dichas entidades no se fundaron con ánimo de ilegalidad, pues desde el mismo momento de su creación solicitaron el oportuno permiso de Loterías, primero en la Generalidad

6. Todas las noticias seleccionadas en el periódico El País durante la década de los 80 se corresponden con noticias sobre empleo protegido.

7. "La Once y los minusválidos denuncian las rifas ilegales" $\left(\mathrm{ABC}_{3} / \mathrm{IO} / \mathrm{I}_{985}\right)$. 
de Cataluña, después en los Ministerios pertinentes, pero siempre se les ha ido denegando" ${ }^{8}$.

En ese mismo año, el 24 de Abril, un periodista de ABC en la sección Zigzag, sección de opinión, plantea si los rumores que existen en relación con la posibilidad de que las personas con diversidad funcional física vendan tabaco en las calles no están relacionados con el conflicto antes mencionado:

"Aunque por el momento no lo confirman todas las fuentes consultadas, parece que el Gobierno está dispuesto a conceder a los disminuidos físicos la exclusividad de la venta de tabaco en la calle. Puede haber sido el controvertido sorteo de los minusválidos lo que haya propiciado este gesto de la administración"

El 24 de Diciembre de 1987 trabajadores de la ONCE se manifestaron contra la legalización de un cupón para las personas con diversidad funcional física. Las concentraciones fueron convocadas por UTO, sindicato mayoritario en la Organización Nacional de Ciegos:

“José Ignacio Rodríguez Rodríguez, secretario general de UTO-Madrid, manifestó que rechazaban la creación de nuevos cupones, ya que ello pondría en peligro la estabilidad de los puestos de trabajo de la ONCE, así como supondría un gran riesgo para la entidad. [...] Asimismo señaló que de los dos mil quinientos vendedores de cupones que hay en estos momentos en la Comunidad de Madrid, trescientos de ellos son minusválidos físicos" ${ }^{\circ}$.

Un hecho a destacar, quizás como consecuencia de los debates que se generaron, es la creación de la Fundación ONCE en I988:

"Esta nueva institución se configura como una entidad de ámbito estatal en las que

8. "Cupón del minusválido" (ABC 27/02/I986). 9. "Minusválidos" (ABC 24/04/I986).

Io. "Trabajadores de la Once rechazan la creación de un nuevo cupón para minusválidos" (ABC 24/I 2/I987). están representadas, además de la ONCE, las principales federaciones de minusválidos físicos, psíquicos y sordos. La Organización Nacional de Ciegos de España es la principal fuente de financiación de la Fundación, que recibe el 3 por roo de la venta del cupón para el desarrollo de proyectos en colaboración con centros, asociaciones, empresas y personas individuales" ${ }^{\mathrm{I}}$.

En 1991, La Asociación de Minusválidos Españoles (AME) anunció su intención de proceder a la recogida de firmas necesarias para llevar al Parlamento la solicitud de que «la ONCE se transforme en una entidad abierta al grueso de los minusválidos físicos trabajadores en esa entidad para que puedan participar en sus órganos de administración, dirección y gestión en igualdad de derechos con los afiliados a esa Organización»:

"En su comunicado, la AME recuerda que en el primer Consejo de Ministros del nuevo Gabinete se aprobó el real decreto 358/9I, de 15 de marzo, sobre reestructuración de la Organización Nacional de Ciegos, en el que «se sanciona definitivamente el monopolio antijurídico y antisocial que supone la tenencia en exclusiva de un cupón a favor del colectivo de invidentes, relegando cualquier referencia a otros colectivos de disminuidos a una pobre y desafortunada redacción, párrafo en el que se señala que la ONCE podrá formalizar convenios con el Ministerio de Trabajo para la atención de otros minusválidos. Esto nos hace suponer que el nuevo Gobierno se dispone a seguir en la línea de favorecer a una Organización hoy convertida en un poder fáctico propio de una multinacional»" ${ }_{\text {I2 }}$.

Una respuesta realizada por un portavoz de la ONCE en dicha noticia dice lo siguiente:

"La ONCE absorbió a 7.808 vendedores de

Prodiecu en julio de I988 y otros minusválidos

I I. "Crear empleo para minusválidos, objetivo de la Fundación ONCE” (ABC I $5 / 09 /$ I 988 ). I2. "Los minusválidos españoles quieren que la ONCE se transforme en una entidad abierta" (ABC 26/03/I99I). 
que se incorporaron en aquel momento por tener un grado de minusvalía superior al $30 \%$, el mínimo exigible por el INSERSO. Ese mismo año se creó la Fundación ONCE, dirigida especialmente a fomentar el empleo de minusválidos no ciegos.

En cuanto a la participación de minusválidos físicos en los órganos de difusión de la Organización, el portavoz subraya que sólo tienen entrada en los mismos los afiliados, «que son invidentes porque se trata precisamente de la Organización Nacional de Ciegos de España»" ${ }^{13}$.

Lo que acontece detrás de este conflicto es la gestión de las Loterías del Estado como un poderoso medio de financiación. Pero además, la defensa de un modelo de integración laboral, que perdura en nuestros días, y que tiene sus raíces en el tardo-franquismo. Es un modelo de integración que nace de la beneficencia, aunque el trabajo de vendedor de lotería no lo consideramos como tal, y que situamos en las representaciones sociales anteriores a la Ley de Integración Social del Minusválido. El conflicto narrado muestra la existencia de unos actores en pugna como evidencia de las re-configuraciones que acontecieron en el campo de la diversidad funcional (Ferreira, 2010) durante los 80 en España.

En un memorándum presentado, en el año I986, por la Comisión de las Comunidades Europeas al Consejo de Ministros de la CEE se plantea que "el problema del empleo y el desempleo de los minusválidos presenta gran complejidad. [...] La Comisión considera esencial dar mayor importancia a la capacidad de los minusválidos y subrayar que incluso las deficiencias más graves suponen una limitada serie de minusvalías" ${ }^{{ }^{4} 4}$. Veintiún millones de europeos en edad laboral, equivalentes a un ro \% de la población total, son personas con diversidad funcional según el estudio presentado por la Comisión de las Comunidades Europeas al Consejo de Ministros de la CEE.

I3. "La respuesta de la ONCE" (ABC 26/03/I99I). I 4. "CEE: Igualdad de oportunidades para los minusválidos" (ABC I4/og/I986).
Según las recomendaciones de dicha Comisión, los países miembros deberían establecer en unos compromisos numéricos la contratación de estas personas en empresas públicas y privadas. Esos compromisos numéricos ya fueron definidos en el texto de la LISMI (I982) ${ }^{\mathrm{I}}$ :

“Art. 38. Uno. Las empresas públicas y privadas que empleen un número de trabajadores fijos que exceda de cincuenta vendrán obligadas a emplear un número de trabajadores minusválidos no inferior al dos por ciento de la plantilla."

Además, dicha Ley establece, en su artículo I 2 (I), un sistema especial de prestaciones sociales y económicas para dichas personas que por no desarrollar una actividad laboral no estén incluidos en el campo de aplicación del sistema de la Seguridad Social. Además, la propia Ley prevé que:

Art. 4I. Uno. Los minusválidos que por razón de la naturaleza o de las consecuencias de sus minusvalías no puedan, provisional o definitivamente, ejercer una actividad laboral en las condiciones habituales, deberán ser empleados en Centros Especiales de Empleo, cuando su capacidad de trabajo sea igual o superior a un porcentaje de la capacidad habitual que se fijará por la correspondiente norma reguladora de la relación laboral de carácter especial de los trabajadores minusválidos que presten sus servicios en Centros Especiales de Empleo.

Art. 4I. Dos. Cuando la capacidad residual de los minusválidos no alcanzara el porcentaje establecido en el apartado anterior accederán en su caso a los Centros Ocupacionales previstos en el título VIII de esta Ley.

I 5. El Real Decreto I45I/I983, de I I de mayo, por el que en cumplimiento de lo previsto en la Ley I3/I982, de 7 de abril, se regula el empleo selectivo o las medidas de fomento del empleo de los trabajadores minusválidos, impone la obligatoriedad de reservar el $2 \%$ de los puestos de trabajo en las empresas con más de cincuenta empleados para personas con diversidad funcional. Y en relación con el empleo en las administraciones públicas, la Ley 30/I984 de Medidas para la Reforma de la Función Pública, establece, en su artículo I9, una reserva del $3 \%$ en las ofertas de empleo público. 
Art. 53. Uno. Los Centros Ocupacionales tienen como finalidad asegurar los servicios de terapia ocupacional y de ajuste personal y social a los minusválidos cuya acusada minusvalía temporal o permanente les impida su integración en una Empresa o en un Centro Especial de Empleo.

Pero el informe de la Comisión Europea platea un abanico más amplio de temas que va más allá de la reserva de cuotas: los avances tecnológicos como una esperanza y una amenaza, programas de desarrolla regional, iniciativas locales, cooperativas o pequeñas y medianas empresas, proyectos de formación para la creación de sus propios negocios, nuevos sistemas telefónicos, la jornada parcial, fondos públicos para la contratación y la formación específica, para la adecuación de la maquinaria, acceso al lugar de trabajo y costes suplementarios de personal, y consideraciones entorno al sistema de Seguridad Social.

Durante los 80 , observamos como la falta de aplicación, principalmente, de la cuota del $2 \%$ en empleo privado y del $3 \%$ en empleo público generará diferentes protestas y reivindicaciones desde el movimiento asociativo. En palabras de Matías Sainz, el presidente de la Coordinadora de Minusválidos Físicos de Cantabria, en I988:

\footnotetext{
"Sabemos que es una utopía el pleno empleo para todos los minusválidos, pero hay una ley de integración social del disminuido, y el primero que la incumple es el Gobierno. Un estudio señala que si el 2 por Ioo de los puestos de trabajo de la Administración estuviera ocupado por minusválidos, en tres años, el 80 por Ioo de este grupo estaría empleado" ${ }^{16}$.
}

\subsection{Década de los 90}

En la década de los 90 la tasa de paro en nuestro país alcanzará unos porcentajes históricos siendo del $22,4 \%, 23,9 \%, 22,7 \%, 22 \%$, y $20,6 \%$ en

I6. "Acusan al Gobierno de incumplir la ley de integración social del minusválido” (ABC Io/I I/I988). el arco que va de I993 a I997, respectivamente. La década se cierra con un descenso de dicha tasa que alcanza, en 1999, un I 5,6\%. La tasa de paro para el conjunto de personas con diversidad funcional, en I999, fue del 26, I \% $(\text { IO,5 puntos por encima de la población total })^{17}$.

Un acontecimiento relevante que reconfigura, una vez más, el campo de la diversidad funcional es la creación del CERMI (Comité Español de Representantes de Minusválidos) en el año I993. El CERMI adquirió personalidad jurídica el 9 de enero de I997, como una asociación de ámbito estatal creada al amparo de la Ley de Asociaciones de 1964. Sin embargo, por vía de hecho, el CERMI nació ya en I993, fruto del acuerdo de las seis principales organizaciones de ámbito estatal de personas con diversidad funcional (COCEMFE, FEAPS, CNSE, FIAPAS, ASPACE y ONCE), proyecto al que fueron sumándose otras entidades representativas.

En I994, coincidiendo con el Día Internacional de las Personas con Discapacidad, aparece tanto en ABC como en El PAÍs dos noticias donde la Confederación Coordinadora Estatal de Minusválidos Físicos de España (COCEMFE) hace público un manifiesto en el que informa de que son más de un millón las familias españolas que conviven con una persona con diversidad funcional física, de los que sólo un Io por ıoo dispone de un puesto de trabajo y menos de un tercio tiene algún tipo de pensión o subsidio ${ }^{\text {I8 }}{ }^{\text {19}}$.

Estamos ante algunas de las consecuencias de la LISMI, es decir, las medidas que dicha Ley establece en materia de empleo-que hemos enumerado en apartado anterior-. Por un lado, como veremos, las cuotas establecidas para la integración laboral en empleos ordinarios no se están cumpliendo 20 . Por otro lado, las pensiones

I7. Encuesta sobre Discapacidades y Deficiencias, I999. I 8. "Un millón de minusválidos físicos pide más atención social y laboral" (ABC 04/I2/I994).

I9. "Los discapacitados reclaman más ayudas y trabajo" (EL PAÍS 04/I 2/I994).

20. También es importante aclarar que en España no predominan empresas con plantillas superiores a 50 trabajadores. Más bien sucede lo contrario, es decir, tienen mayor presencia las pequeñas y medianas empresas que suelen tener plantillas inferiores a 50 trabajadores. 
y subsidios reconocidos en dicha ley no alcanzan a toda la población considerada (muchos y muchas no tienen el certificado que reconoce su diversidad funcional) y en la mayoría de los casos, dichas pensiones, no alcanzan el salario mínimo interprofesional.

En 1994 el número de personas con diversidad funcional física ronda el millón de habitantes, de los cuales I 24.970 personas ( I 2,5\%) cobran una pensión no contributiva por invalidez -lo que supuso un gasto bruto para el Estado, a Octubre de I994, de 5.OI4 millones de pesetas (30 millones de euros aproximadamente)-. En I996, el índice de paro entre las personas con diversidad funcional física es del $67 \%{ }^{21}$. En este contexto, la plataforma PREDIF (Plataforma Representativa Estatal de Personas con Discapacidad Física) va a proponer un discurso diferente a la LISMI. PREDIF propone una argumentación que se apoya en un análisis microeconómico del gasto que supone para el Estado una pensión no contributiva y el ahorro que supone mantener a una persona empleada. Llegan a la conclusión de un ahorro para el Estado de 9I4.000 pesetas al año por cada persona con diversidad funcional empleada (actualmente: 5.493,25 euros) ${ }^{22}$.

En I995 COCEMFE pidió al Gobierno -con motivo de la celebración del Día Internacionalque apruebe un plan de acción para personas con diversidad funcional. COCEMFE instó al Gobierno y a las Administraciones autonómicas a activar las medidas necesarias, para mejorar el sistema de contratación de dichas personas, puesto que la integración laboral «es la piedra angular de la normalización» ${ }^{23}$. También pidió al Parlamento la modificación de la Ley de Pensiones no Contributivas, ya que su contenido «no respeta al discapacitado físico como persona individual $»^{24}$.

2I. "El índice de paro entre los minusválidos físicos se acerca al 70 por ciento" (ABC 02/04/1996).

22. Una argumentación similar la veremos en la crítica del Foro de Vida Independiente en relación con el coste-plaza de una persona en una residencia y el presupuesto que esa misma persona necesita para contratar a un asistente personal. 23. "La COCEMFE pide al Gobierno la aprobación inmediata del plan de acción para los discapacitados" (EL PAIS 03/I 2/I995).

24. "La COCEMFE pide al Gobierno la aprobación inme-
Existe un modelo, que vincula educación-empleointegración. Este modelo se ha defendido durante mucho tiempo y se sigue defendiendo. Pero en la actualidad, algunas autores, empiezan a ser críticos con un eje tan lineal. Por ejemplo, Abberley (I998) plantea si la utopía de la integración a través del trabajo no encierra una cierta trampa y plantea qué pasa con aquellas personas que no son capaces de producir valor económico. Por su parte, Díaz Velázquez (20I0), desde el marco teórico de la ciudadanía, va a plantear que más allá de las dimensiones de la producción y el consumo existen otras áreas de la vida en la que las personas con diversidad funcional están excluidas (participación política, cultura, ocio, relaciones sociales, sexualidad, etc.).

En I997, el ministro de Trabajo Javier Arenas, junto con miembros del CERMI presentan a la Reina Doña Sofía un plan de empleo para personas con diversidad funcional ${ }^{25}$ que entre las principales medidas que contempla está hacer cumplir las famosas cuotas del $2 \%$ para las empresas privadas y del $3 \%$ para empresas públicas. En I998, coincidiendo con el día internacional de las personas con diversidad funcional, Javier Arenas anuncia sanciones para las empresas que no cumplan con dichos $\operatorname{cupos}^{26}$.

"Según Arenas «la autentica integración social de los disminuidos no se producirá hasta que no haya tenido lugar su integración laboral»" ${ }^{27}$.

Una vez más vemos repetidos los mismos hechos y discursos: falta de aplicación de las medidas legislativas contempladas en la LISMI y la defensa de la integración laboral como principal vía para la integración social. Un ejemplo más lo encontramos en una noticia que nos habla de la Confederación Andaluza de Minusválidos Físicos:

diata del plan de acción para los discapacitados" (EL PAIS 03/I 2/I995).

25. "Arenas presenta a la Reina el plan de empleo para discapacitados" (ABC 04/I I/I997).

26. "Siete de cada diez minusválidos en edad laboral están en paro” (EL PAÍS 04/I 2/I 998 ).

27. "Arenas presenta a la Reina el plan de empleo para discapacitados” (ABC 4/I I/I997). 
"Hoy por hoy, entre un $60 \%$ y $70 \%$ de los discapacitados no tienen empleo. El año pasado la CAMF recibió más de 200 millones del Instituto Andaluz de Servicios Sociales para el desarrollo de proyectos de formación y de empleo" ${ }^{28}$.

En la década del 2000 nacerá el Foro de vida independiente y las Oficinas de Vida Independiente, volviendo a reconfigurar el campo de la diversidad funcional y los discursos que obtienen mayor legitimidad. Comenzarán a aparecer críticas al gasto que implica las estructuras organizativas del movimiento asociativo de corte más tradicional, a la institucionalización en residencias y se defenderá la figura del «asistente personal». En este sentido, las Oficinas de Vida Independiente han denunciado el fracaso parcial de gastos en formación y estructuras organizativas, y defienden que la mayor parte del presupuesto asignado y recaudado debería ir destinado a programas de vida independiente que permitan a las personas con diversidad funcional disfrutar de los recursos comunitarios existentes.

Por otro lado, otra parte del movimiento asociativo sigue defendiendo la necesidad de recursos específicos ante la insuficiencia e ineficacia de los recursos comunitarios. Un ejemplo lo vemos en el texto de la siguiente noticia:

"Las medidas que lleva a cabo la Consejería de Economía [de la Comunidad de Madrid] a favor de las personas con discapacidad son insuficientes para la Federación de Asociaciones de Disminuidos Físicos de la Comunidad (FAMMA): «No realiza ninguna política activa de empleo y, además, sustituye los Servicios de Integración Laboral por pobres acciones de orientación que no contribuyen a los objetivos de la inserción laboral $»^{29}$.

28. "La Confederación de Minusválidos creará este año un millar de empleos" (EL PAÍ́S 24/04/I998).

29. "Los discapacitados critican la falta de políticas de empleo de la Comunidad de Madrid" (ABC 21/05/200I).

\subsection{Primera década del 2000}

La primera década del nuevo milenio se abrirá con un descenso prolongado de la tasa de paro que en su primer año se sitúa en el I 3,9\% (este descenso es una tendencia que se inicia en I998) y que culmina en el año 2007 (un año antes de la crisis económica internacional) con una tasa de paro del 8,3\%. En 2008, la tasa volverá a subir hasta el I I, 3 \%; en 2009, se disparará al I $8 \%$; en 20 IO alcanza nuevamente el límite del $20 \%$; y en 20 I 2 , se sitúa en el $25 \%$ (el porcentaje más alto del periodo analizado $)^{30}$. Para las personas con diversidad funcional legalmente reconocidas, en 2012 , la tasa de paro fue de 8 , I puntos superior, es decir, del $33, \mathrm{I} \%$.

La constatación del insuficiente grado de cumplimiento de la cuota del $2 \%-y$ otros intereses que este estudio no puede poner de manifiesto- dio lugar al establecimiento de medidas alternativas y mecanismos de control. Esta necesidad se hizo pública, por primera vez, en el año I 997 cuando se aprobó un plan específico a favor de la ocupación de las personas con diversidad funcional, con el objetivo de poner en práctica una serie de medidas urgentes para la promoción de la ocupación de estas personas. Pero no fue hasta el año 2000, mediante el Real Decreto 27/2000 de $\mathrm{I} 4$ de enero ${ }^{3 \mathrm{I}}$, cuando las empresas obligadas a cumplir el $2 \%$ pueden empezar a aplicar las medidas alternativas siguientes (artículo 2):

- Realización de un contrato mercantil o civil con un centro especial de empleo, o con un trabajador autónomo discapacitado, para el suministro de materias primas, maquinaria, bienes de equipo, o de cualquier otro tipo de bienes necesarios para el normal desarrollo de la actividad de la empresa que opta por esta medida.

30.Fuente: Banco Mundial. Databank (http://data.worldbank. org/).

3I. Real Decreto 27/2000, de I4 de enero, por el que se establecen medidas alternativas de carácter excepcional al cumplimiento de la cuota de reserva del 2 por 10 on favor de trabajadores discapacitados en empresas de 50 o más trabajadores. 
- Realización de un contrato mercantil o civil con un centro especial de empleo, o con un trabajador autónomo discapacitado, para la prestación de servicios ajenos y accesorios a la actividad normal de la empresa.

- Realización de donaciones y de acciones de patrocinio, siempre de carácter monetario, para el desarrollo de actividades de inserción laboral y de creación de empleo de personas con discapacidad, cuando la entidad beneficiaria de dichas acciones de colaboración sea una fundación o una asociación de utilidad pública cuyo objeto social sea, entre otros, la formación profesional, la inserción laboral o la creación de empleo en favor de los minusválidos que permita la creación de puestos de trabajo para los mismos $\mathrm{y}$, finalmente, su integración en el mercado de trabajo.

Estas medidas se vieron ampliadas con la regulación de los enclaves laborales, cuyo Real Decreto 290/2004 ${ }^{32}$ contempla entre sus objetivos facilitar a las empresas el cumplimiento de la cuota de reserva legal del $2 \%$. Los enclaves laborales se entienden como una subcontratación de obras o servicios entre un centro especial de empleo y una empresa ordinaria, siendo una medida de utilidad para favorecer el tránsito desde el empleo protegido al empleo ordinario.

En relación con el empleo público, el Real Decreto 227I/2004, de 3 de diciembre, aumentaba la cuota del $3 \%$ al $5 \%$. Posteriormente será modificada por la Ley 7/2007, de I2 de Abril, del Estatuto Básico del Empleo Público, donde se establece en su artículo 59 que en las ofertas de Empleo Público se reservará un cupo no inferior al $7 \%$.

En 2006, aparece en El PAÍS una noticia que vuelve a poner de relieve el incumplimiento por parte de las empresas de las cuotas establecidas:

32. Real Decreto 290/2004, de 20 de febrero, por el que se regulan los enclaves laborales como medida de fomento del empleo de las personas con discapacidad.
"Un total de 360 compañías de más de 50 trabajadores fueron investigadas en Cataluña al haberse detectado que incumplían la ley. De ellas, I 80 seguían vulnerando la norma pese al requerimiento de los inspectores. A causa de las actuaciones de Inspección de Trabajo, las empresas investigadas contrataron a 200 discapacitados o adoptaron alguna de las medidas alternativas que prevé la ley, como la contratación de servicios a centros especiales de ocupación" ${ }^{33}$.

En el último año del periodo analizado, 20I2, volvemos a observar como los incumplimientos de la LISMI, treinta años después de su aprobación, sigue siendo uno de los temas más recurrentes entre la administración y el movimiento asociativo:

"Ana Mato, Ministra de Sanidad, Igualdad y Servicios Sociales dice que «promoverá medidas como el cumplimiento de esta reserva del $2 \%$ y otras como contratos en el sector público" ${ }^{34}$.

"COCEMFE «advierte de que son necesarias aumentar las inspecciones»" ${ }^{35}$.

Seis días después del anuncio de la Ministra Ana Mato aparece una nueva noticia en $\mathrm{ABC}$ :

"Los inspectores de Trabajo se van a encargar de velar por que las empresas de más de 50 trabajadores cumplan con la ley vigente y reserven un $2 \%$ de sus puestos de trabajo a personas con algún tipo de discapacidad. Según informó a $\mathrm{ABC}$ el nuevo director general de Discapacidad, Ignacio Tremiño, desde el Ministerio de Sanidad, Igualdad y Servicios Sociales ya se está trabajando con el de Trabajo para que sus inspectores se involucren en esta tarea" ${ }^{36}$.

33. "Ocho de cada diez empresas incumplen la obligación de contratar a discapacitados" (EL PAIS 26/02/2006).

34. "Si me contratas te demostraré que tengo más ganas que nadie" (ABC 24/OI/20I2).

35. "Si me contratas te demostraré que tengo más ganas que nadie" ( $\mathrm{ABC} 24 / 0 \mathrm{I} / 20 \mathrm{I} 2$ ).

36. "Los inspectores de trabajo obligarán a contratar el $2 \%$ de discapacitados" (ABC 30/OI/20I2). 
En un informe realizado por la Organización Mundial de la Salud, en 2002, se destaca en relación con el empleo que:

\footnotetext{
"Las personas con discapacidad tienen entre dos y tres veces más posibilidades de estar desempleadas. Por ello, la deteriorada situación económica que sufren muchas de ellas está vinculada al difícil acceso que tienen al mundo laboral.
}

Una situación que se produce debido a una combinación de factores, entre los que se incluyen unos niveles formativos inferiores -muchos no poseen formación reglada alguna- así como una serie de prejuicios, como que no trabajan, que no pueden tener especialización o que sólo pueden desempeñar empleos marginales. Además, el informe señala que son contratadas para empleos en los que se les paga menos y en los que tienen pocas posibilidades de promoción profesional.

Una circunstancia que se produce a pesar de que las políticas de empleo para estas personas han experimentado un cambio importante en los últimos años. Así, una de las medidas adoptadas para favorecer la integración, como el sistema de cuotas -que obliga a las empresas a reservar un porcentaje de puestos para trabajadores con discapacidades generalmente incumplida en todos los países ante la pasividad de los gobiernos y autoridades. Tanto es así que la UE se está planteando la obligatoriedad del cumplimiento por parte de las empresas de las normas antidiscriminación existentes como uno de los condicionantes para optar a los concursos públicos" ${ }^{37}$.

En las últimas noticias analizadas, del año 20I2, comienzan a emerger discursos que alertan de la reducción del gasto público con motivo de la crisis de deuda pública que viven las administraciones públicas:

37. "Los discapacitados, ciudadanos de segunda en «prácticamente todos los países de la Tierra" ( $\mathrm{ABC}$ 22/I2/2002).
"Según la Fundación Ecom, que agrupa a más de 180 asociaciones que trabajan con personas con discapacidad física, el sector quedará «herido de muerte» por los recortes, en este caso impulsados por el Gobierno central, que afectarán a la partida sobre políticas activas de empleo. Las entidades aseguran que la Generalitat prevé que los 400 millones que el Servicio de Ocupación de Cataluña (SOC) destinó en 20I I a las organizaciones colaboradoras, entre ellas Ecom, queden reducidos en $\mathrm{I} 80$ millones” ${ }_{38}$.

Las noticias analizadas nos muestran, en materia de empleo ordinario, que tanto las esperanzas que generó la LISMI como su falta de aplicación es el tema que tiene más presencia. A su vez, las cuotas establecidas para empleo privado y público es el tema que genera más debate. En la primera década del año 2000, el movimiento asociativo exige mayores inspecciones para el cumplimiento de dichas cuotas y critica el elevado número de personas que permanecen inactivas y conformes con el sistema de prestaciones públicas. Sorprende la poca prensa que se tiene la LIONDAU (Ley de Igualdad, No Discriminación y Accesibilidad Universal, de 2 de diciembre del 2003). Al igual que tampoco se incida en otras medidas relacionadas con la integración laboral como los incentivos a los empleadores (fiscales, laborales o para la adaptación de los puestos de trabajo), que tienen por objetivo reforzar la contratación.

\section{4. Un breve apunte estadístico}

Aunque la tasa de paro en España es relevante tanto para las personas con diversidad funcional como para la población general, nos parece importante destacar que en la última década el porcentaje de personas con diversidad funcional que se muestran activas ha ido aumentando. En 20I2, según la Base Estatal de Datos de Personas con Discapacidad, había en España 3.478.395 registros correspondientes a personas que les ha sido valorado su grado de diversidad

38. "Uno de cada tres discapacitados perderá su empleo por los recortes" (EL PAÍS I/O5/20I2). 
funcional. De éstas, el grupo de personas que han resultado con un grado de diversidad funcional igual o superior al $33 \%$ y como tal con la consideración de personas en situación de

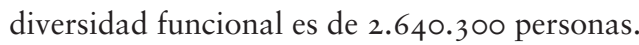
De dicho conjunto las personas en edad de trabajar, entre los I 6 y los 64 años, según el informe elaborado por el INE "El Empleo de las Personas con Discapacidad” en 20I2, fue de un total de 1.450 .800 personas, lo que supone un $4,8 \%$ de la población total en edad de trabajar. A continuación (Tabla 2) se muestra un desglose de dicho número de personas según su actividad:

El porcentaje de actividad de ambos sexos $(36,6 \%)$ todavía muestra grandes diferencias en relación con la población general, donde el mismo porcentaje es 40 puntos superior $(77,0 \%)$. A pesar del elevado número de personas con diversidad funcional que permanecen inactivas (9I9.200 personas en 20I2) observamos como en la serie revisada, 2008-20I2, el porcentaje de personas inactivas ha ido disminuyendo. En 20I3, la tasa de actividad aumentó al 37,4\%, lo que representa la noticia más positiva en las tres décadas analizadas.
Según los datos estadísticos del INE, antes mencionados, los asalariados con diversidad funcional en empresas de más de 50 trabajadores, exceptuando los Centros Especiales de Empleo, eran I34.700 -el 4I \% pertenece a personas empleadas en el sector público $(55.200)$ y el $59 \%$ pertenece a personas empleadas en el sector privado (79.500)-. Lo que representa un $37,9 \%$ de la población con diversidad funcional ocupada en 2012 (355.500) y un $43, \mathrm{I} \%$ de la población asalariada con dichas características (3 I 2.840), lo importante es destacar es que desde 2008 la tendencia ha sido positiva, a excepción del último año de la serie 2008-20I2 (Tabla 3).

Aunque se puede hacer una valoración positiva de los logros conseguidos por el sistema de cuotas en las tres décadas transcurridas desde que se estableció la LISMI, una conclusión que es compartida por diferentes actores sociales del sector de la diversidad funcional es que la medida de discriminación positiva establecida por la cuota del $2 \%$ es insuficiente. En primer lugar, porque en las tres décadas transcurridas desde la aprobación de la LISMI todavía existe un número desconocido de empresas

Tabla 2. Personas con discapacidad según sexo y situación de actividad

\begin{tabular}{|l|c|c|c|c|c|}
\hline \multirow{2}{*}{} & \multicolumn{2}{|c|}{ Valores absolutos en miles } & \multicolumn{2}{c|}{ Porcentajes (\%) } \\
\cline { 2 - 6 } & Total & Hombres & Mujeres & Hombres & Mujeres \\
\hline Total & $\mathbf{1 . 4 5 0 , 0 0}$ & $\mathbf{7 9 0 , 5}$ & $\mathbf{6 6 0 , 3}$ & $\mathbf{5 4 , 5}$ & $\mathbf{4 5 , 5}$ \\
\hline Activos & 531,6 & 310,2 & 221,4 & 58,3 & 41,7 \\
Ocupados & 355,5 & 297 & 148,5 & 58,2 & 41,8 \\
Parados & 176,1 & 103,2 & 72,9 & 58,6 & 41,4 \\
\hline Inactivos & 919,2 & 480,3 & 438,9 & 52,3 & 47,7 \\
\hline
\end{tabular}

Fuente: Instituto Nacional de Estadística.

Tabla 3. Asalariados con diversidad funcional en empresas, públicas y privadas, con más de $\mathbf{5 0}$ trabajadores. Unidades en miles de personas

\begin{tabular}{|l|c|c|c|c|c|}
\hline & $\mathbf{2 0 0 8}$ & $\mathbf{2 0 0 9}$ & $\mathbf{2 0 1 0}$ & $\mathbf{2 0 1 1}$ & $\mathbf{2 0 1 3}$ \\
\hline Asalariados con diversidad funcional & 86,3 & 115,5 & 132,3 & 138 & 134,7 \\
\hline
\end{tabular}

Fuente: Elaboración propia a partir de datos del INE. 
que incumplen dicha ley. En segundo lugar, por qué se desconoce el impacto que están teniendo las medidas alternativas al sistema de cuotas en el número de personas empleadas en el mercado ordinario. Lo que no quiere decir que dicho impacto sea negativo, pero si puede estar incidiendo en la calidad de los contratos realizados. Y en tercer lugar, el límite de tamaño de las compañías que establece la legislación española en lo que se refiere a las personas con diversidad funcional no tiene en cuenta las particularidades de la demografía empresarial española. Según el informe elaborado por la consultora KPMG (2OII):

$$
\begin{aligned}
& \text { "La cuota alemana, por ejemplo, alcanza al } \\
& 5 \% \text { de los empleados en compañias de más } \\
& \text { de } 20 \text { trabajadores. En el caso de España el } \\
& \text { tamaño de las compañias a las que aplica } \\
& \text { la cuota es de } 5 \text { empleados. Teniendo en } \\
& \text { cuenta que el tamaño medio de las compañias } \\
& \text { españolas es, en términos de empleados, la } \\
& \text { mitad de las alemanas, puede afirmarse que } \\
& \text { el potencial número de puestos de trabajo } \\
& \text { que podrían ser ocupados por personas con } \\
& \text { discapacidad en España están muy lejos del } \\
& \text { equivalente alemán” (49-50). }
\end{aligned}
$$

Otra medida establecida por la LISMI son las ayudas públicas a las personas con diversidad funcional. Según una nota de prensa elaborada por el INE sobre el informe "El empleo de las personas con discapacidad", en 2012 , "en el caso específico de las personas con discapacidad el sistema público de prestaciones benefició a 788.400 ( 54 de cada I00). De ellas, un I 8,6\% (I46.400 personas) eran activas” (I I). En 20I3, "el sistema público de pensiones benefició a 822.600 ( 57 de cada I00) personas con discapacidad. De ellas, un 2I,7\% (I 78.800 personas) eran activas" (2OI3: II).

Esto supone que el número de personas en edad laboral con dichas características que perciben una prestación sigue siendo muy elevado. Y de éstas, las que permanecen en activo, el porcentaje es pequeño. Por lo que el modelo de la LISMI, en relación con las prestaciones sociales, supone un gasto social muy elevado. Según KPMG (20II):
"Desde el punto de vista del gasto público, conviene recordar asimismo el carácter permanente de las ayudas públicas a las personas con discapacidad. Tal y como muestran los estudios desarrollados al efecto por organizaciones internacionales como la OCDE, la salida de una persona con discapacidad del mercado laboral tiene carácter casi permanente. Esto es, la probabilidad de que una persona que recibe subsidios por discapacidad se reincorpore al mercado laboral es reducida. De este modo, las iniciativas y el apoyo público al empleo de las personas con discapacidad tiene como contrapartida una disminución que podríamos denominar estructural y de largo plazo sobre el gasto social y reduce las presiones sobre el estado del bienestar" (34).

En relación con los incentivos para el fomento de la contratación, el informe del INE para $20 \mathrm{I} 2$ nos dice que "el $25 \%$ de las personas con discapacidad ocupadas que cotizaron a la Seguridad Social tenía algún tipo de deducción en las cotizaciones. Estas deducciones, tuvieron mayor efecto sobre los asalariados que sobre los trabajadores por cuenta propia. Y el $24,9 \%$ de los asalariados con discapacidad tenía la modalidad de contrato específico de discapacidad" (2013: IO). En 2013, dichos porcentajes aumentaron a un $26,6 \%$.

A pesar del alto porcentaje de personas con diversidad funcional que permanecen inactivas los datos muestran tendencias positivas en la tasa de actividad, en el número de asalariados que trabajan en empresas de más de 50 trabajadores, en el número de personas que permanecen activas aún percibiendo una prestación y en el número de personas que se ven beneficiadas por las medidas de fomento del empleo para el colectivo de personas con diversidad funcional. Si estas tendencias se ven modificadas en los últimos años analizados, parece ser, no se ha constatado, que se debe a la incidencia de la crisis económica internacional, a la recepción económica, a la deuda pública de las administraciones y a los recortes presupuestarios acontecidos en los últimos años. 


\section{Empleo protegido.}

La LISMI (I982) establece que son Centros Especiales de Empleo aquellos que, participando regularmente en operaciones de mercado, tengan como objetivo principal, junto con el de realizar un trabajo productivo, el asegurar el empleo remunerado y la prestación de aquellos servicios de ajuste personal y social a estos trabajadores con diversidad funcional, procurando a la vez constituir el medio de integración del mayor número de ellos al régimen normal de trabajo en empresas ordinarias.

"El Servicio Técnico del Fondo de Solidaridad, antiguo Fondo Nacional de Protección al Trabajo, califica a los Centros Especiales de «instrumentos de integración e instrumentos de paso hacia una empresa ordinaria»" 39 .

"González de Lena, subdirector de Negociación Colectiva y Condiciones de Trabajo del Ministerio de Trabajo y artífice principal del real decreto que regula la relación laboral del minusválido, afirma que «el trabajo es una de las formas de integración habituales, por lo que los Centros Especiales constituyen el medio idóneo para aprender a trabajar»" ${ }^{40}$.

La LISMI tendrá como consecuencia más directa la creación de Centros Especiales de Empleo y Centros Ocupacionales. Según el informe sobre centros especiales de empleo de KPMG (20II: 4-5) se observan cuatro momentos clave en la creación de este tipo de centros:

I. En el año i982 con la publicación de la LISMI I3/I982, en la que se definía por primera vez el centro especial de empleo.

2. Se observa un ligero crecimiento en los años I 986 y 1987 que podría deberse a la publicación de dos Reales Decretos,

39. "La integración laboral del minusválido tropieza con la falta de dinero para hacer cumplir la ley" ( $\left.\mathrm{ABC}_{3} / \mathrm{IO}_{1} / \mathrm{I} 85\right)$. 40. "La integración laboral del minusválido tropieza con la falta de dinero para hacer cumplir la ley" ( $\mathrm{ABC}_{3} / \mathrm{IO}_{\mathrm{I}} 985$ ). el 2273/I985 y el I368/I985, que desarrollaban la legislación que regula los centros especiales de empleo.

3. Hacia el año I 998 se publicó la Orden del Ministerio de Trabajo y Asuntos Sociales que establecía las bases reguladoras para la concesión de las ayudas y subvenciones públicas destinadas a la integración laboral de las personas con discapacidad. Este puede ser un factor de explicación en la creación de centros especiales de empleo.

4. El cuarto de ellos se produjo en el año 2000 y pudo deberse a la publicación del Real Decreto 27/2000, por el que establecían medidas alternativas de carácter excepcional al cumplimiento de la cuota de reserva del $2 \%$ a favor de trabajadores discapacitados de empresas de 50 o más trabajadores.

Otra novedad, a partir del Real Decreto 290/2004 de 20 de Febrero, son los Enclaves Laborales que se regulan como medida de fomento del empleo de las personas con diversidad funcional. Los Enclaves Laborales -como comentábamos con anterioridad- se conciben como «medio de transición» hacia el empleo ordinario y como medio para que las empresas del sector público y privado conozcan mejor las capacidades y aptitudes reales de los trabajadores con diversidad funcional, como paso previo a su eventual incorporación a la plantilla de la empresa4 ${ }^{\mathrm{I}}$.

En 2004, en El PAÍS, aparecerá una noticia que hemos querido destacar por sostener un discurso diferente a los expuestos más arriba.

"La comunidad foral [de Navarra] cuenta con un total de $\mathrm{I} 3$ centros especiales que acogen en régimen de empleo protegido a I.500 trabajadores. Se dedican a actividades

4I. Aunque esta nueva medida del gobierno central se encuentra en una frontera difusa entre el trabajo ordinario y el empleo protegido hemos querido comprenderla dentro de este apartado porque su discurso guarda cierta semejanza con los testimonios presentados en relación con los centros especiales de empleo en la década de los 80 . 
subcontratadas de montaje industrial y al sector servicios (jardinería, limpieza, hostelería). Creados en la mayoría de los casos por fundaciones y asociaciones sin ánimo de lucro, estos centros reciben importantes subvenciones públicas y cumplen una notable labor social, pero el modelo, asegura José Elizalde (portavoz del sindicato CCOONavarra y autor del informe), "ha fracasado como medio para la progresiva inserción de los trabajadores en el mercado ordinario»".

“La reserva para minusválidos del $2 \%$ de los puestos de trabajo en empresas ordinarias resultó ser un mecanismo totalmente insuficiente para promover la integración de los discapacitados. En 2000, la ley se cambió y desde ese momento se permitió a las industrias sustituir esa cuota por la subcontratación de tareas con los centros de empleo protegido. «Con el tiempo esa modificación se ha convertido en un mecanismo perverso", dice Elizalde”.

“Además, los centros resultan deficitarios en su mayoría. Sus pérdidas oscilan entre los 48.000 y los 240.000 euros. Para tapar los agujeros, la Administración foral, que ya paga el $50 \%$ del salario mínimo por trabajador y bonifica y exime las cuotas patronales de la Seguridad Social, debe subvencionar el déficit para equilibrar las cuentas de empresas fundadas por instituciones de apoyo a disminuidos físicos y psíquicos y personas en riesgo de exclusión social como Aspace, Anfas o Anasaps" ${ }^{42}$.

Sobre una población activa total en España que se sitúa alrededor de los 22 millones de personas, en $20 \mathrm{II}$, los centros especiales de empleo suponen un $0,4 \%$ del total: 70.000 trabajadores (de los cuales 64.39I son personas con algún tipo de diversidad funcional). Lo que supone un porcentaje de $5, \mathrm{I} \%$ en relación con la población con diversidad funcional en edad de trabajar en 20 I I (I.450.800), un I $4 \%$ en relación con la población activa con diversidad funcional (46I.600) y un I9 \% en

42. "Condenados a la exclusión social" (EL PAÍS 2I/04/2004). relación con la población ocupada con las mismas características (337.300). El informe de KPMG (20II) nos muestra que dichos centros han destruido menos empleo que el mercado ordinario desde que comenzó la crisis internacional. Algunos actores defienden la necesidad de los centros especiales de empleo para aquellas personas que necesitan más apoyos y tienen menos capacidades para producir valor económico en el mercado ordinario. Pero desconocemos qué función están cumpliendo en relación con el tránsito de personas del mercado protegido al mercado ordinario.

La LISMI estructuró las políticas públicas en materia integración laboral en tres espacios: empleo ordinario (cuota del $2 \%$ y el $3 \%$ ), centros especiales de empleo y centros ocupacionales. Tres espacios, que se vieron ampliados a cinco con la creación de los Enclaves Laborales (2004) y el programa de empleo con apoyo regulado por el Real Decreto $870 / 2007^{43}$. Y que está destinado a aquellas personas que cumplen con alguno de los siguientes requisitos:

Artículo 3. Destinatarios finales. I.

a) Personas con parálisis cerebral, personas con enfermedad mental o personas con discapacidad intelectual con un grado de minusvalía reconocido igual o superior a $33 \%$.

b) Personas con discapacidad física o sensorial con un grado de minusvalía reconocido igual o superior al $65 \%$.

Otro ejemplo de integración laboral lo encontramos en las empresas de inserción:

"En total hay cerca de 200 en España, donde trabajan unas 4.000 personas, en números redondos, sujetas al convenio colectivo del sector que corresponda. A pesar de que reciben subvenciones, generan retornos a

43. RD $870 / 2007$, de 2 de julio, por el que se regula el programa de empleo con apoyo como medida de fomento de empleo de personas con discapacidad en el mercado ordinario de trabajo. 
las arcas públicas. Un estudio de la Obra Social de Caixa Catalunya de hace unos años calculaba que estos empleos ahorraban al Estado 28 millones de euros. Y otro informe más reciente, elaborado para la Federación de Asociaciones Empresariales de Empresas de Inserción (Faedei) revelaba que comunidades, como Canarias, recibían en retornos más del $43 \%$ de lo empleado, y en otras, como Castilla y León, el dinero volvía duplicado" ${ }^{44}$

En las bases de datos analizadas no existen datos directos sobre el impacto de las diferentes medidas. Por ejemplo, desconocemos el número de empresas que no cumplen la cuota del $2 \%$, desconocemos el número de contratos que se han realizado en relación con las medidas de carácter excepcional a las cuotas del $2 \%$, el número de personas empleadas en enclaves laborales, el número de personas que se están beneficiando de los programas de empleo con apoyo, etc. La información de la que disponemos sólo nos permite hacer una valoración general del impacto de las diferentes medidas para la integración laboral de aquellas personas con un grado de diversidad funcional igual o superior al $33 \%$.

\section{La dimensión simbólica del empleo}

En dicho contexto, marcado por el desempleo, unas tasas de actividad, en general, que han ido en aumento desde principios del siglo XXI y una opinión pública cada vez más sensibilizada en torno a la integración laboral de las personas con diversidad funcional, constatamos una idea que aparece repetida en diferentes noticias y enunciada por diferentes actores sociales: $\mathrm{el}$ empleo es la vía principal para la integración social. Este discurso vincula la participación al eje de la producción y el consumo, es decir, se refuerza la idea de que la capacidad productiva resulta determinante para la inclusión social. La otra cara de este discurso son los riesgos de

44. "Las empresas de inserción resisten a la crisis en nuevos nichos de mercado" (El País 5/05/20Io). exclusión social, que se ven contrarrestados con medidas de prestaciones públicas y recursos familiares:

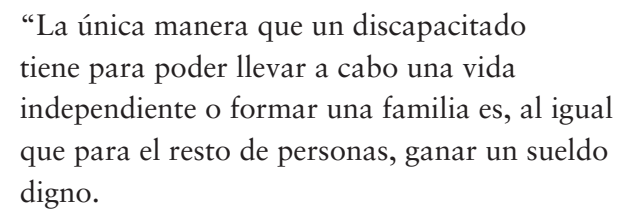
tiene para poder llevar a cabo una vida independiente o formar una familia es, al igual que para el resto de personas, ganar un sueldo digno.

Lo que podría parecer una obviedad es un asunto grave teniendo en cuenta que los discapacitados tienen unas necesidades especiales, con lo que si no ganan el dinero suficiente para cubrirlas se convierten en personas dependientes. Esa dependencia tiene un doble impacto.

El primero, para sus familiares, que deben hacerse cargo de ellos. El segundo, un impacto psicológico para los propios discapacitados, que llegan a considerarse como una carga o un estorbo para sus familiares y amigos, lo que acarrea serios problemas psicológicos" ${ }^{45}$.

Pero la población activa (con diversidad funcional) se enfrenta también a prejuicios a la hora de ser contratados. Como consecuencia de ello, acontecen en la prensa opiniones que al querer sensibilizar constituyen, al mismo tiempo, un juicio sobre el propio grupo. Vemos muy repetido en relación con la integración laboral lo que se podría denominar «la carga de la prueba», es decir, cuando las personas con diversidad funcional se enfrentan a un empleo tienen que demostrar que son capaces de hacerlo mejor que nadie:

"En este tiempo de trabajo en común he aprendido mucho de los minusválidos -que hoy son más de la mitad de una plantilla de 150 personas- $y$ he podido constatar su perfecto rendimiento" (Francisco Carabel, profesor de Balcarsa: fábrica gallega de joyería para disminuidos físicos ${ }^{46}$.

45. "Sólo uno de cada diez discapacitados tiene trabajo estable" (ABC 4/I 2/2006).

46. "Minusválidos, oficiales de oro" (ABC 7/02/I983). 
“Tenemos que convencer [a los empresarios] de que no sólo son rentables, sino que rinden un poco más" (José Gómez Amate, presidente de CAMF: Confederación Andaluza de Minusválidos Físicos) ${ }^{47}$.

"Francisco Mesonero, director general de la Fundación Adecco, expresa a ABC que «el trabajo de una persona discapacitada no sólo no menoscaba, si no que en muchos casos favorece la actividad de la empresa", porque suelen trabajar con más ilusión, esfuerzo y aprovechan una oportunidad que, saben, no se les presenta a menudo" ${ }^{48}$.

“ «Si me contratas, voy a tener la oportunidad de demostrarte que voy a hacer el trabajo igual que cualquier otra persona, que voy a tener más ganas que nadie y que le voy a dar un aire nuevo a tu empresa. Si más empresarios hacen lo que tú, entre todos vamos a hacer un mundo mejor». Esta es la llamada de Luis Castro, el nombre supuesto de un joven con síndrome de Down, realiza en un «video curriculum» colgado en internet que ha logrado cerca de I00.000 visitas en cuatro días" ${ }^{49}$.

En este mismo contexto, las noticias analizadas nos hablan de la emergencia de nuevos discursos entorno a las posibilidades de integración que las nuevas tecnologías pueden permitir:

\begin{abstract}
"La peculiar experiencia formativa, única en España, parte del convencimiento de que las comunicaciones generadas a través de la red suponen un espacio laboral inmejorable en donde el minusválido podrá competir en igualdad de condiciones si se prepara adecuadamente" (Carlos Mauricio Bernal, coordinador del departamento de Trabajo y Formación de la Asociación) $)^{50}$.
\end{abstract}

"Éste puede hacerse desde casa, o sin la obligación diaria de desplazarse a otro lugar

47. "Los discapacitados accederán en dos años a una bolsa de empleo regional" (EL PAÍS 8/09/I998).

48. "Discapacitados frente a la crisis" ( $A B C 2$ I/08/2009).

49. "Si me contratas te demostraré que tengo más ganas que nadie" ( $\mathrm{ABC} 24 / 0 \mathrm{I} / 20 \mathrm{I} 2)$.

50. "Una experiencia inédita" (EL PAÍS 8/I I/200I). y el teletrabajo puede aplicarse a todas las tareas de externalización de empresas: contabilidad, mailing... basta con tener un equipo informático”. (Ma Jesús Sanz, Jefa de Programas de Discapacidad de los Servicios Sociales de la Comunidad de Madrid) ${ }^{5}$.

Todos los tópicos identificados están relacionados con lo que actualmente muchos autores y autoras denominan ideología de la normalidad (Brogna, 2006; Ferreira y Caamaño, 2007; Palacios y Buffini, 2007). En este marco de referencia, los individuos con insuficiencias están obligados a asumir tantas funciones «normales» como puedan, y de la mejor forma posible.

Según Mark Oliver (I998), las personas con discapacidad se vieron discriminadas por la emergente sociedad industrial y ha sido ésta la que ha definido las capacidades que eran válidas para la misma. En relación con la producción, como reconoce Finkelstein (citado por Abberley, I998: 87) "es posible que una sociedad esté dispuesta, y en determinadas circunstancias llegue a ansiarlo, a absorber en el mercado laboral a una porción de su población con insuficiencias, pero esto puede producir el efecto de mantener y quizá de intensificar la exclusión del resto”. En palabras de Abberley (I998: 9I) "una teoría utópica alternativa puede ser la que ofrezca otro futuro en la medida en que rechace el «trabajo» como elemento esencialmente definitorio de la participación social”.

Sugiere Díaz Velázquez (20I0: I23) "la necesidad de reforzar necesariamente otros elementos sociales que vinculen a estas personas con la ciudadanía (la visibilidad en el entorno, la participación social y politica, la promoción de las virtudes cívicas basadas en la comunicación interpersonal), así como orientar el concepto de interdependencia y de aportación a la sociedad, bajo otras dimensiones más allá del cálculo de la aportación económica como productividad social".

5I. "Diez mil discapacitados físicos podrán trabajar desde casa a través de Internet" ( $\mathrm{ABC}$ I8/03/2003). 


\section{Conclusiones}

El empleo es un tema muy presente en la prensa, que ha generado diferentes posiciones discursivas en torno a cómo conseguir el acceso al mercado laboral por parte de las personas con diversidad funcional. Sobre todo, porque a pesar de las fluctuaciones de las tasas de desempleo, entre las personas con diversidad funcional, durante el periodo analizado -con especial relevancia a partir de 2007 con la crisis económica internacional- las tasas han sido siempre superiores a la media de la población general. De aquí, que se hayan hecho diferentes planteamientos, no exentos de polémicas en determinados momentos históricos: los intereses por la venta de cupones, como medio de financiación, enfrentó a diferentes organizaciones del sector; el incumplimiento de la reserva de cupo conllevó a la necesidad de establecer nuevas medidas para regular medidas alternativas; también se han definido medidas para el fomento de la contratación (contratos específicos, bonificaciones en las cotizaciones, subvenciones para la adecuación de los puestos de trabajo, etc.); se han creado los enclaves laborales como lugares de tránsito entre el empleo protegido y ordinario; se han aprobado programas de empleo con apoyo; se ha reconocido la figura del asistente personal; etc.

En materia laboral, la LISMI ha sido todo un referente durante los ochenta y noventa, generando una forma de entender la integración laboral a través de diferentes espacios: el empleo ordinario, los centros especiales de empleo y los centros ocupacionales. La falta de aplicación de la reserva de cupo, recogida en la ley, ha sido motivo de aparición de constantes noticias en la prensa, por parte del movimiento asociativo, de los diferentes partidos políticos, de los sindicatos, etc. De hecho, es el tema con más presencia en la prensa en lo referido al empleo y el que ha generado más debate y posiciones discursivas. Asimismo, un discurso comúnmente repetido y defendido es la consideración del empleo como vía para la integración social, siendo un mensaje que refuerza la idea de que la capacidad productiva resulta determinante para la inclusión social.

En relación con las medidas alternativas a las cuotas del $2 \%$, el principal argumento que se repite una y otra vez es que éstas se establecieron para hacer cumplir la Ley. Pero desconocemos por qué las correspondientes empresas eludían dicha Ley, por qué existen empresas que siguen sin cumplirla y, sobre todo, el impacto que dichas medidas han tenido en la primera década del 2000 , es decir, que se está viendo más beneficiado el empleo ordinario o protegido. Aún así, con los datos disponibles, la tendencia de personas con diversidad funcional empleadas en empresas, públicas y privadas, de más de 50 trabajadores ha sido positiva; representando, en 20I 2 , un 43 , I \% de la población asalariada con dichas características (3 I 2.840).

Un dato igualmente revelador es el aumento del número de personas con diversidad funcional activas, lo que significa un cambio en positivo en la concepción de pasar de sujetos pasivos a sujetos activos. Las personas receptoras de algún tipo de prestación (788.400) representaban, en $20 \mathrm{I} 2$, el $85,7 \%$ de la población inactiva (919.200). De las que reciben una prestación, un I 8,6\% ( 146.400 personas) eran activas. En algunos casos, con el cumplimiento de las políticas integración laboral, este gasto social puede ser revertido. En otros, este es un gasto social necesario para todas aquellas personas que se encuentran en una situación de incapacidad o no pueden producir valor económico.

El $25 \%$ de la población ocupada con diversidad funcional participó de las deducciones en las contrataciones y de contratos específicos. Desconocemos el impacto que dichas medidas está teniendo en la clase empresarial. Y pensamos que habría que estar atentos a la evolución de dichos datos en las próximas décadas. Por otro lado, señalar que las personas empleadas en centros especiales de empleo representan, en $201 \mathrm{I}$, un I $4 \%$ en relación a la población activa y un I9 \% en relación a la población ocupada. En estos tiempos de crisis, el empleo protegido ha destruido menos puestos de trabajo que el mercado ordinario. 
A nivel macrosocial, nos parece interesante poder saber que incidencia están teniendo las medidas de fomento del empleo en la clase empresarial, el número de personas que han conseguido un empleo ordinario gracias a las medidas de carácter excepcional a las cuotas de discriminación positiva, las personas empleadas en «enclaves laborales», cuántas personas participan de programas de empleo con apoyo y cuántas personas que disfrutan de una «asistente personal» se mantienen ocupadas. En un nivel microsocial se hace necesario hacer una apuesta por metodologías cualitativas que desvelen los "prejuicios", "estereotipos", "discriminaciones" y "violencias estructurales" que viven dichas personas en su día a día.

\section{Referencias bibliográficas}

Abberley, P. (I998): “Trabajo, utopía e insuficiencia”, en L. Barton (Comp.): Discapacidad y Sociedad (77-98). Madrid: Ed. Morata.

Brogna, P. (2006): El nuevo paradigma de la discapacidad y el rol de los profesionales de la rehabilitación, Argentina: Cisne.

Caamaño, M.J.R. y Ferreira, M.A.V. (2006): "Sociología de la Discapacidad: una propuesta teórica crítica". Nómadas: revista crítica de ciencias sociales y jurídicas, Vol. I3, no. I (2006), p. 243-249.

Díaz Velázquez, E. (2010). “Ciudadanía, identidad y exclusión social de las personas con discapacidad". Política y Sociedad, 47 (2): I I 5 I 35 .

España. Ley 7/2007, de I 2 de Abril, del Estatuto Básico del Empleo Público, Boletín Oficial del Estado, núm. 89, de I 3 de abril de 2007, pp. I6270 a I6299.

España. Ley I3/I982, de 7 de abril, de Integración Social de los Minusválidos (LISMI), Boletín Oficial del Estado, núm. I03, de 30 de abril de I982, pp. I I IO6 a IIII 2.

España. Real Decreto 27/2000, de I4 de enero, por el que se establecen medidas alternativas de carácter excepcional al cumplimiento de la cuota de reserva del 2 por 100 en favor de trabajadores discapacitados en empresas de 50 o más trabajadores, Boletín Oficial del Estado, núm. 22, de 26 de enero de 2000 , pp. 34 IO a $34 \mathrm{I} 2$.

España. Real Decreto 290/2004, de 20 de febrero, por el que se regulan los enclaves laborales como medida de fomento del empleo de las personas con discapacidad, Boletín Oficial del Estado, núm. 45, de 2I de febrero de 2004, pp. 8386 a 839 I.

España. Real Decreto 2271/2004, de 3 de diciembre, Boletín Oficial del Estado, núm. 303 , de I7 de diciembre de 2004, pp. 4I26I a 4I 264 .

Ferreira, M. A. (20I0): "De la minus-valía a la diversidad funcional: un nuevo marco teóricometodológico". Politica y Sociedad, 47 (2): $45-65$.

Iáñez, A. (20Iо). Prisioneros del cuerpo. La construcción social de la diversidad funcional. A Coruña, Diversitas.

IMSERSO. Base de datos Estatal de personas con discapacidad (en línea). http://www.imserso. es/imserso_or/documentacion/estadisticas/ bd_estatal_pcd/index.htm . 
Instituto Nacional de Estadística (2OI2). El Empleo de las Personas con Discapacidad. Serie 2008-20I2 (en línea). http://www.ine.es/ jaxi/menu.do? type $=$ pcaxis $\&$ path $=/ t_{22} /$ p $_{3} 20 /$ serie\&file=pcaxis .

Instituto Nacional de Estadística (201 2). El empleo de las personas con discapacidad. Informe de los datos para 20I I (en línea). http://www.ine. es/prensa/np753.pdf.

Instituto Nacional de Estadística (2013). El empleo de las personas con discapacidad. Informe de los datos para $20 \mathrm{I} 2$ (en línea). http://www.ine. es/prensa/np82I.pdf.

Instituto Nacional de Estadística (20I4). El empleo de las personas con discapacidad. Informe de los datos para 20I3 (en línea). http://www.ine. es/prensa/np883.pdf.
KPMG (20I3) "Presente y Futuro de los Centros Especiales de Empleo". Fundosa Galenas S.A.U. (en línea). http://www.feaps.org/files/ Documentos/CEEcompleto.pdf».

Oliver, M. (I998): “¿Una sociología de la discapacidad o una sociología discapacitada?”, en L. Barton (Comp.): Discapacidad y Sociedad. Madrid: Ed. Morata.

Palacios, A. y Buffini, F. (2007): La discapacidad como una cuestión de derechos humanos. Una aproximación a la Convención Internacional sobre los Derechos de las Personas con Discapacidad, Madrid: Ed. Cinca.

Romañach, J. y Lobato, M. (2005). Diversidad funcional, nuevo término para la lucha por la dignidad en la diversidad del ser humano (en línea). 〈http://www.forovidaindependiente.org/ node/ $45^{\prime}$. 